\title{
Influence of climate on winter wheat productivity in different climate regions of China, 1961-2000
}

\author{
Yanling Song ${ }^{1,2, *}$, Deliang Chen ${ }^{3,4}$, Wenjie Dong ${ }^{3}$
}

${ }^{1}$ Chinese Academy of Sciences Key Laboratory of Regional Climate-Environment Research for Temperate East Asia, START Regional Center for Temperate East Asia, Institute of Atmospheric Physics, Qijiahuozi Road, Chaoyang, Beijing 100029, China

${ }^{2}$ Graduate School of the Chinese Academy of Sciences, 19 Yuquan Road, Shijingshan, Beijing 100049, China

${ }^{3}$ National Climate Center, China Meteorological Administration, 46 Zhongquancun Road, Beijing 100081, China

${ }^{4}$ Earth Sciences Centre, University of Gothenburg, Box 460, 40530 Göteborg, Sweden

\begin{abstract}
The World Food Studies crop model (WOFOST) was tuned and validated with observed meteorological data as well as winter wheat growth and yield data for 50 stations in 12 provinces in China from 1998 to 2003. The results show that most of the simulated growth dates and yields lie within $\pm 15 \%$ range of the observed data, showing that the genetic parameters determined are reasonable in most winter wheat regions of China. Overall, the results demonstrate that the WOFOST model predicts potential winter wheat yields (assuming there are no limits imposed by water availability) and growth reasonably well under current climatic conditions. By assuming winter wheat varieties and agricultural practices stay constant, the parameterization obtained by the tuning was then used to model the impacts of climate on winter wheat growth for the 50 stations using long-term weather data from 1961 to 2000 . Over this period, the simulated potential yield of winter wheat in northern China increased by $2.3 \%$, while decreasing by $1.6 \%$ in southern China. In northern China, the accumulated negative temperatures during winter increased by $29.3^{\circ} \mathrm{C}$ decade ${ }^{-1}$, which is most likely the main reason for the increased potential yield of winter wheat. In southern China, one possible reason for the decreased potential yield is a shortened growth interval for winter wheat caused by the increasing mean temperatures.
\end{abstract}

KEY WORDS: Crop growth model $\cdot$ WOFOST $\cdot$ Climate change $\cdot$ Winter wheat $\cdot$ China

\section{INTRODUCTION}

Chinese agriculture has undergone tremendous structural changes over the last decades. The average staple crop productivity has doubled in $25 \mathrm{yr}$ while the population has increased by $25 \%$ (CSY 2003). Winter wheat is one of China's most important staple food crops, with a total farming area of nearly 24 million ha and a production exceeding 92 billion $\mathrm{kg}$ in 2002 (CSY 2003). Although China has been the world's largest wheat producer since 1983 (FAOSTAT data 2004), exports have only exceeded imports since 2001 (according to CSY 2002) or 2003 (according to FAOSTAT data, 2004; available at http://faostat.fao.org/). Following World Trade Organization agreements, China's decreasing import tariffs are likely to raise the demand for land-intensive cultivation, such as wheat, for the domestic market (FAO 2002).

Winter wheat growth and productivity is sensitive to temperature and precipitation, which determine both phenological development and growth rates (Bauer et al. 1984). The East Asian monsoon system has a tendency to cause low temperatures and regional to largescale droughts in the northern China, and high temperatures, continuous rain, severe floods and hail storms in southern China. These meteorological disasters have adverse effects on all forms of agriculture, including winter wheat. As a result winter wheat production fluctuates inter-annually with varying meteorological conditions (e.g. Tao et al. 2004).

In addition to interannual variation, climate in China is in the process of change. The average annual tem- 
perature for China as a whole has increased by 0.5 to $0.7^{\circ} \mathrm{C}$ (Wang et al 2004), while total precipitation has decreased (Zhai et al 1999) over the last 50 yr. Moreover, for the period 1990 to 2100 the global surface air temperature is projected to increase by 1.4 to $5.8^{\circ} \mathrm{C}$ as a result of increasing concentrations of atmospheric carbon dioxide and other greenhouse gases (IPCC, 2001). Consequently the regional climate in China will also be affected (Ding et al. 2006, Qian et al. 2004).

To assess possible impacts of climate variability and change on crop production, crop models have been extensively applied (Riha et al. 1996, Dai 1997, Lin et al. 1997, Zhang \& Wang 1998, Hulme et al. 1999, Lal et al. 1999, Mavromatis \& Jones 1999, Alexandrov \& Hoogenboom 2000, Xiong et al. 2001). While many studies for China have focused on rice production (e.g. Ge 2002), relatively few have dealt with wheat. Recently, Wu (2003) conducted an experiment for $2 \mathrm{yr}$ (2000-2001) at Yucheng experiment station $\left(116^{\circ} 36^{\prime} \mathrm{E}\right.$, $\left.36^{\circ} 57^{\prime} \mathrm{N}\right)$, Shandong province. The author retrieved a series of parameters for WOFOST which must be changed according to different winter wheat cultivars, soil types and climate conditions. This setup of the model will also be used in this study.

To understand the impacts of climate change on agricultural productivity and operations in the future, it is necessary to investigate how agriculture has responded to the historic climate change. Climatic variables such as air temperature, wind speed and solar radiation all have their roles in determining productivity. It is the combined effect of all the climatic variables that has the greatest impact on yields. To understand the relative role played by the changes in the various climatic variables, including increased air temperature, a crop model was used to simulate potential yields of winter wheat. The objectives of the present study were to tune and validate the WOFOST model with observations from 12 provinces in China, and to assess the influence of climate change on winter wheat between temperate, semi-humid regions and warm, humid climate regions of China during 1961-2000. In particular, the different influences of historic climate change on productivity of winter wheat were identified for the climate regions of China. By excluding the effects of precipitation, the present study focused on the climatic effects of temperature, solar radiation, air humidity and wind.

\section{MATERIALS AND METHODS}

\subsection{Study area}

Winter wheat is planted in Shandong, Hebei, Shanxi, Shaanxi and Henan provinces in northern China as well as in Jiangshu, Anhui, Hubei, Sichuan, Chongqing, Guizhou, Yunnan provinces in southern China (Fig. 1). In northern China, the winter wheat region has an annual mean temperature of 11.2 to $14.4^{\circ} \mathrm{C}$. Summer is rainy and hot (monthly mean temperatures range from 22 to $28^{\circ} \mathrm{C}$ ) whereas winter is dry and cold (monthly mean temperatures range from -10 to $1^{\circ} \mathrm{C}$ ). The total annual precipitation generally ranges from 400 to 1000 mm (China Meteorological Administration 2000) depending on circulation patterns and topographic features. While in southern China, most of the winter wheat region lies in warm and humid monsooncontrolled climatic zones. Temperature in winter is higher than that in northern China $\left(0\right.$ to $\left.5^{\circ} \mathrm{C}\right)$, summer is hot $\left(25\right.$ to $\left.28^{\circ} \mathrm{C}\right)$. The precipitation is around 800 to $1500 \mathrm{~mm}$.

For this analysis the winter wheat regions in China are divided into 50 ecological zones based on climate, soil, land use and current agriculture practices (China Meteorological Administration 2000). Hence 50 stations, 1 representative for each zone were selected and winter wheat growth and yields were simulated for these stations (Fig. 1).

\subsection{The WOFOST model}

WOFOST (World Food Studies) originated in the framework of interdisciplinary studies on world food security and potential world food production. The latest version (7.1.2) was issued in 2002 and is available as freeware on the internet (www.alterra.wur.nl). Supit et al. (1994) and Boogaard et al. (1998) describe the model in detail.

WOFOST was developed to simulate the effect of cultivar, planting density, weather, soil water and nitrogen on crop growth, development and yield. The model has been used for crop growth monitoring (Lanen et al. 1992), potential yield forecasting on regional and national scales (Rötter 1993, Wolf 1993), as well as for climate change impact scenarios (van Diepen et al. 1987, Wolf \& van Diepen 1991, Wolf 1993). Furthermore, the model has been applied in different climatic regions (Wolf et al. 1989, Savin et al. 2001), including northern China (Wu 2003). Wu conducted an experiment over 2 successive years (20002001), in which crop growth was monitored every $5 d$, including tiller (a growing stage of winter wheat) number, leaf area index, fresh and dry weight of all organs, filling rate and plant height. The model was calibrated to obtain values of the parameters using the experimental data in 2001, and then validated with data from 2000. The following crop growth simulation results were examined: potential production, water-limited production, potential total above-ground dry matter 


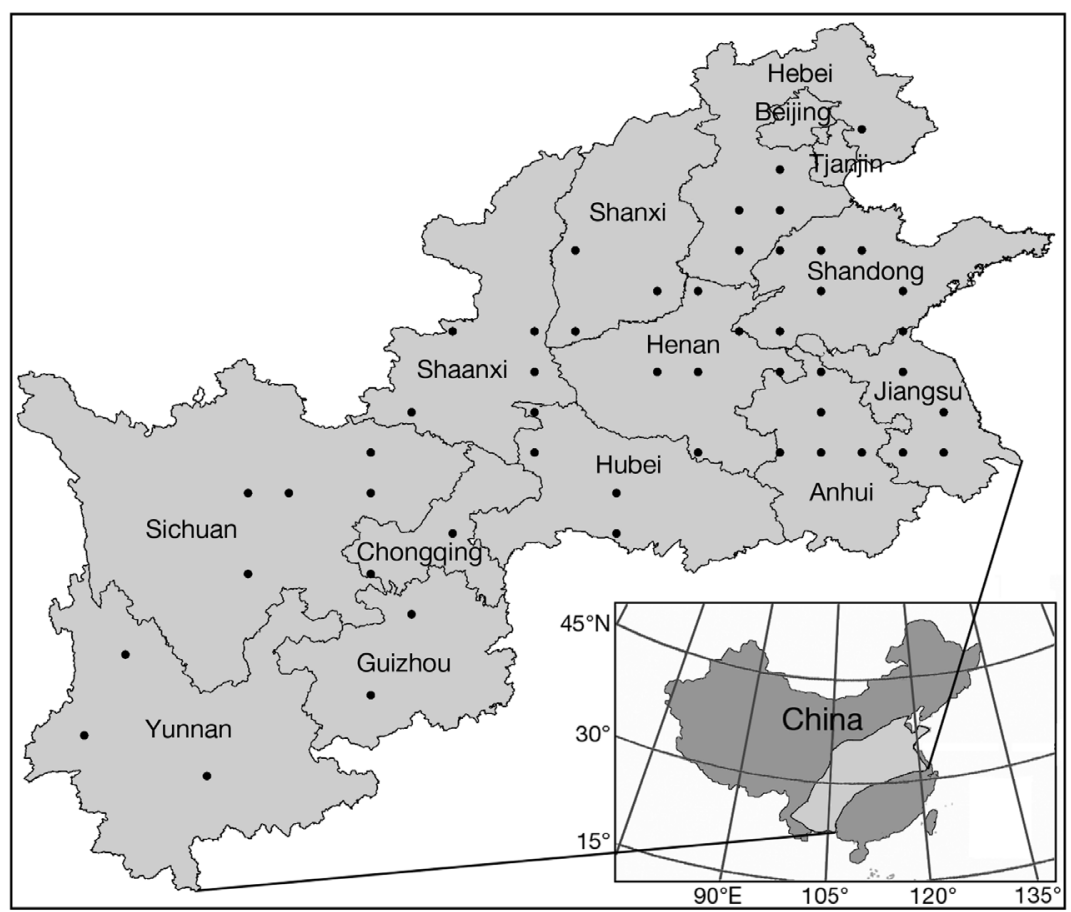

Fig. 1. Locations of the agrometeorological stations in the winter wheat regions of China

and water limited total above-ground dry matter, potential and water-limited leaf area index, potential and water-limited stem weight. Comparison between measurements and simulations shows that the performance of the model is reasonable in terms of the high correlation coefficient. We concluded that: (1) the WOFOST model is suitable for the northern China Plain in terms of the detailed description of crop photosynthesis and properly simulated crop potential growth; (2) WOFOST treats some processes in a simplified way and requires only basic input, which makes it possible to use the model for larger regions.

The WOFOST model simulates crop growth on the basis of the underlying processes, such as photosynthesis and respiration, and how these processes are influenced by environmental conditions. Dry matter accumulation for a crop can thus be calculated as a function of meteorological variables including irradiation, temperature, and wind speed, as well as crop characteristics.

\subsubsection{Weather}

The meteorological variables used in WOFOST are: maximum temperature, minimum temperature, global radiation, wind speed, vapor pressure, potential evapotranspiration and rainfall. WOFOST uses the Penman method (Penman 1948) to calculate potential evapotran- spiration. Although snow cover during winter can affect the growth of winter wheat in various ways, there is no description in the model that takes these processes into account. The same is true of the effect of flooding.

\subsubsection{Crop growth}

WOFOST describes phenological development, growth and yield formation of a crop and environmental conditions. The model simulates dry matter accumulation of a crop as a function of irradiation, temperature and crop characteristics using a $1 \mathrm{~d}$ time step. The basis for calculating dry matter production is the rate of gross $\mathrm{CO}_{2}$ assimilation of the canopy. This rate depends on solar radiation absorbed by the canopy and from the absorbed radiation the photosynthetic characteristics of individual leaves, from which the daily rate of $\mathrm{CO}_{2}$ assimilation of crop is calculated. Part of the carbohydrate produced is used to maintain the existing live biomass; the remainder is converted into structural matter.

\subsubsection{Soil water balance}

A crop growth simulation model also has to keep track of the soil moisture content to determine when and to what degree a crop is exposed to water stress. This can be done with the aid of a water balance, which compares, during a given period of time, incoming water in the rooted surface soil with outgoing water, and quantifies the difference between the two as a change in the amount of soil moisture stored. Since this work focuses on the potential yield without water stress, this part of the model is not used.

\subsection{Input data required by the model}

The input data used to run WOFOST includes weather, crop characteristics and soil data. The meteorological data required to estimate wheat growth and yield include daily values of maximum, minimum and mean air temperature, precipitation (not used in this study), early morning vapor pressure, mean wind speed at $2 \mathrm{~m}$ above ground and solar radiation at the surface. Daily weather data for $75 \%$ of the 50 stations 
are available at the agrometeorological stations for the period 1961 to 2003. For the rest, daily weather data were obtained from nearby weather stations within 30 to $40 \mathrm{~km}$ distance, which were provided by the China Meteorological Administration for the same period. All weather data was quality controlled by comparing the measurements with those from neighboring stations and their own long term statistics. Missing values were replaced with the long term daily averages from a neighboring station.

There are 17 genetic parameters of the model, which strongly influence the simulated winter wheat growth. Most parameters are chosen following Wu (2003), and lower threshold temperature for emergence, maximum effective temperature for emergence, temperature sum from sowing to emergence, temperature sum from emergence to anthesis, temperature sum from anthesis to maturity, and maximum leaf $\mathrm{CO} 2$ assimilation rate are tuned to within a reasonable range to fit the modeled results to the observed values. The final parameters used in this research were similar to those of $\mathrm{Wu}$ (2003) in northern China due to similar varieties of winter wheat, but the growing stage parameters including emergence, flowering, and maturity dates are slightly different in southern China due to different varieties of winter wheat. The parameters obtained were based on a tuning and validation process, which is described in sections 2.4 and 3.1 .

WOFOST also requires physical characteristics of soil, such as water retention, hydraulic conductivity and workability for calculating the daily soil water balance. The available water content was estimated from the textural class of the predominant soil. The other soil input data were obtained from the Second Soil Survey (China Soil Survey Office 1995).

\subsection{Tuning and validation of the model}

The model was tuned against observations of flowering and maturity dates, and against yields for all the 50 stations, by changing the genetic parameters. The observations for year 2000 or 2001 were used in the tuning process. The validation period for the model was 1998-1999 and 2001-2003 for 28 stations, and 1998-2000 and 2002-2003 for the remaining 22 stations.

\section{RESULTS AND DISCUSSION}

\subsection{Tuning and validation}

WOFOST was tuned for 28 stations in 2000 and the other 22 stations were adjusted to 2001 when the weather conditions were close to normal and relatively few climate disasters occurred. The soil parameters were set for each station according to previous studies (China Soil Survey Office 1995). The genetic parameters for winter wheat were tuned through simulations since these data were not available for most stations. These parameters were changed to get close agreement between the simulated and observed growth stages and yields. When the simulated flowering and maturity dates agreed (within 10\%), and yields were within $15 \%$ range of the observed values at the same time, the genetic parameters were set and considered to be reasonable. If not, the genetic parameters were further adjusted until the simulated results were within the 10 and $15 \%$ range for the observed growth date, and yield, respectively (Fig. 2).

The crop model was then validated using the observed data during 1998-1999 and 2001-2003 for 28 stations as well as 1998-2000 and 2002-2003 for the remaining 22 stations. The observed data for the validations included flowering, maturity and yield. To aid the comparison of the simulated results with those observed, the following statistics were computed: correlation coefficients (r), bias, relative bias, mean square error (MSE) and relative MSE. Table 1 gives the results of these statistics calculated after the validating process, and with the parameters determined by tuning.

The difference between the simulated and observed dates for flowering and maturity were on average 0.8 and $1.2 \mathrm{~d}$, respectively. The simulated yields agreed well with the observed, with a bias of $6 \%$. Overall, the results demonstrate that the model is skillful in predicting the winter wheat growth and yields in China.

\subsection{Change of growing season}

Climate change during the growing season was first assessed before the simulated impact of the climate change on winter wheat growth was evaluated. The growing season for winter wheat was assumed to be from October to June in northern China and from October or November to May in southern China. The regional climate variables for winter wheat regions of China were based on the observations from the 50 stations. The temperatures and sunshine hours for the growing season of winter wheat are plotted in Fig. 3.

The mean temperature during the growing season shown in Fig. $3 \mathrm{~b}$ has a large interannual variability and an increasing trend with $0.16^{\circ} \mathrm{C}$ decade $^{-1}$ following that of the mean annual temperature over the whole of China (NCC 2000). The decadal mean temperatures increased from $10.3^{\circ} \mathrm{C}$ in the $1960 \mathrm{~s}$ to $10.9^{\circ} \mathrm{C}$ 
in the 1990s. The trends of the temperatures in different regions during 1961-2000 are shown in Fig. 3a. In northern China, the temperature during the growing season of winter wheat increased greatly in Hebei, Shanxi, north of Shaanxi from 0.3 to $0.6^{\circ} \mathrm{C}$ decade $^{-1}$, and in Shandong, Henan, south of Shaanxi from 0.1 to $0.3^{\circ} \mathrm{C}$ decade $^{-1}$, while the increasing temperature trends in southern China are lower than those in the north, with 0.3 to $0.5^{\circ} \mathrm{C}$ decade ${ }^{-1}$ in Jiangshu, Anhui, and Yunnan, and 0.0 to $0.3^{\circ} \mathrm{C}$ decade $^{-1}$ in Sichuan, Chongqing, and Guizhou. The temperatures at Nangong and Bazhong in Sichuan decreased by $0.1^{\circ} \mathrm{C}$ decade $^{-1}$ and $0.03^{\circ} \mathrm{C}$ decade ${ }^{-1}$. Tang et al. (2005) studied temperature variations in China during 1951-2002 and found that there have been increasing trends of mean maximum temperature in northern China, while weak decreasing or no obvious trends are detected in
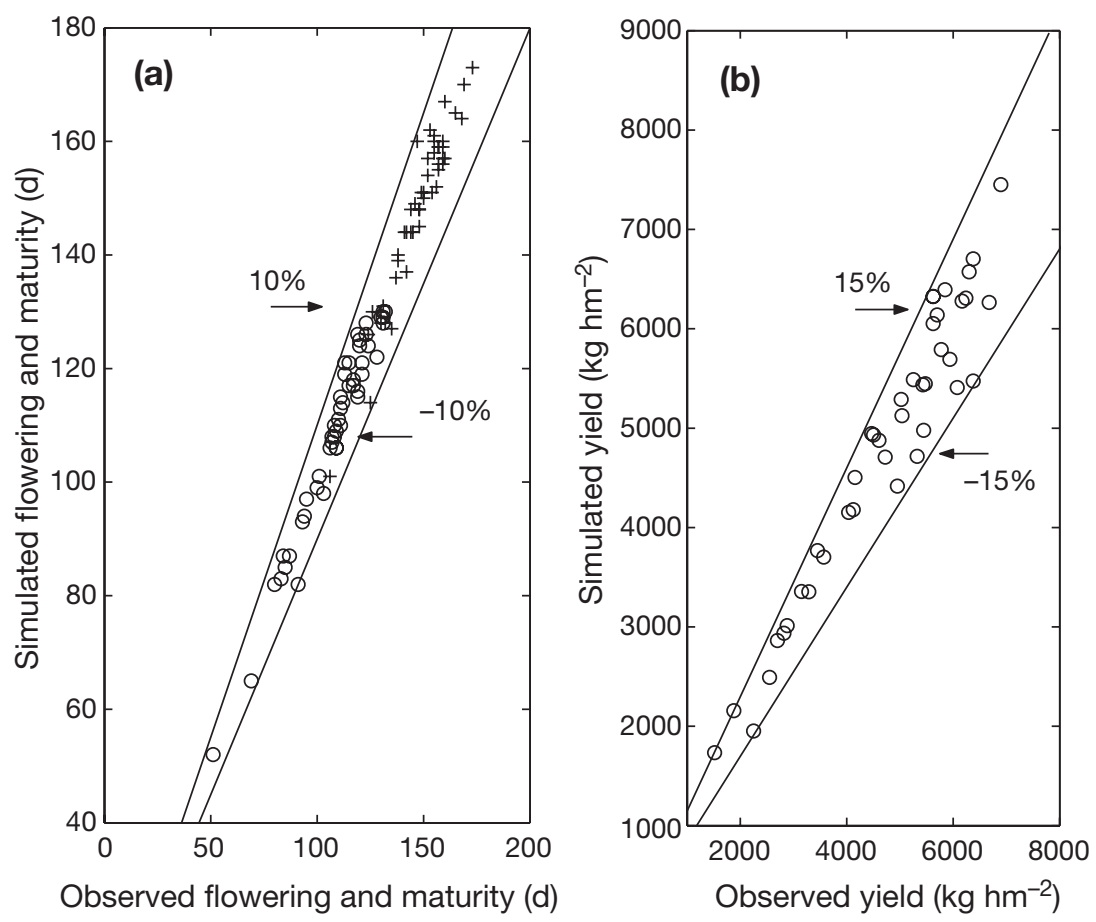

Fig. 2. Simulated (a) growth stages and (b) yields of winter wheat compared with observations for tuning the model for 50 stations in China. (a) $\bigcirc$ and +: flowering and maturity, respectively

Table 1. Analysis of selected variables of model simulations in relation to observations for validating the model. r: correlation coefficients, N: sample size; MSE: mean suquare error

\begin{tabular}{|c|c|c|c|c|c|c|}
\hline & $\mathrm{r}$ & $\mathrm{N}$ & Bias & $\begin{array}{l}\text { Relative } \\
\text { bias (\%) }\end{array}$ & MSE & $\begin{array}{l}\text { Relative } \\
\text { MSE (\%) }\end{array}$ \\
\hline Flowering & 0.95 & 229 & $-0.8 \mathrm{~d}$ & -0.4 & $4.8 \mathrm{~d}$ & 4.9 \\
\hline Maturity & 0.94 & 227 & $-1.2 \mathrm{~d}$ & -0.8 & $4.4 \mathrm{~d}$ & 3.1 \\
\hline Yield & 0.89 & 112 & $174.9 \mathrm{~kg} \mathrm{hm}^{-2}$ & 5.6 & $548.9 \mathrm{~kg} \mathrm{hm}^{-2}$ & 12.2 \\
\hline
\end{tabular}

southern China. In northern China, winter wheat is frequently damaged by low temperature during winter dormancy and flowering in April and May, while in southern China winter wheat is rarely harmed by low temperatures. As a result, the increasing temperature trend can have different influences on winter wheat yield in different regions.

Sunshine hours have been used in the model to estimate solar radiation. The amount of sunshine hours has decreased by $42.4 \mathrm{~h}$ decade ${ }^{-1}$ during the growing season over China (Fig. 3d). In the 1980s and 1990s, the sunshine hours decreased by $131.7 \mathrm{~h} \mathrm{decade}^{-1}$ and $121.4 \mathrm{~h}$ decade $^{-1}$ compared to that in the 1960s. However, the trends of sunshine hours are distributed unevenly in different regions. In northern China (Hebei, Shandong and the north of Shanxi), sunshine hours have decreased by 50 to $202 \mathrm{~h} \mathrm{decade}{ }^{-1}$. While in the more southerly regions of Shanxi, Shaanxi and Henan the decreasing trends are between -50 and $-20 \mathrm{~h}$ decade $^{-1}$. Overall in southern China, sunshine hours decreased 17 to $70 \mathrm{~h}$ decade $^{-1}$.

Recently, Qian et al. (2006) found that in China the total cloud cover and low cloud cover have decreased 0.88 and $0.33 \%$ decade $^{-1}$ during $1954-2001$, and at the same time solar radiation has decreased by $3.1 \mathrm{~W} \mathrm{~m}^{-2}$ decade $^{-1}$. They proposed that increased air pollution may have produced a fog-like haze that reflects/absorbs solar radiation. This result agrees with our findings here, which suggests that the decreased sunshine hours are probably caused by air pollution.

The decreasing sunshine hours are associated with reduced solar radiation, which will have adverse effects on winter wheat growth ( $\mathrm{Hu}$ et al. 2005). There are 3 main ways in which radiation is important for plant life (Hamlyn 2000). First, some of the solar radiation absorbed by winter wheat is used for the synthesis of energy-rich chemical bonds and reduced carbon compounds. Second, radiation is the major mode of energy exchange between the wheat plant and the aerial environment. Thirdly, the amount and spectral distribution of shortwave radiation regulate crop growth and development. Sunshine duration is used as an indicator of solar radiation in this study. 

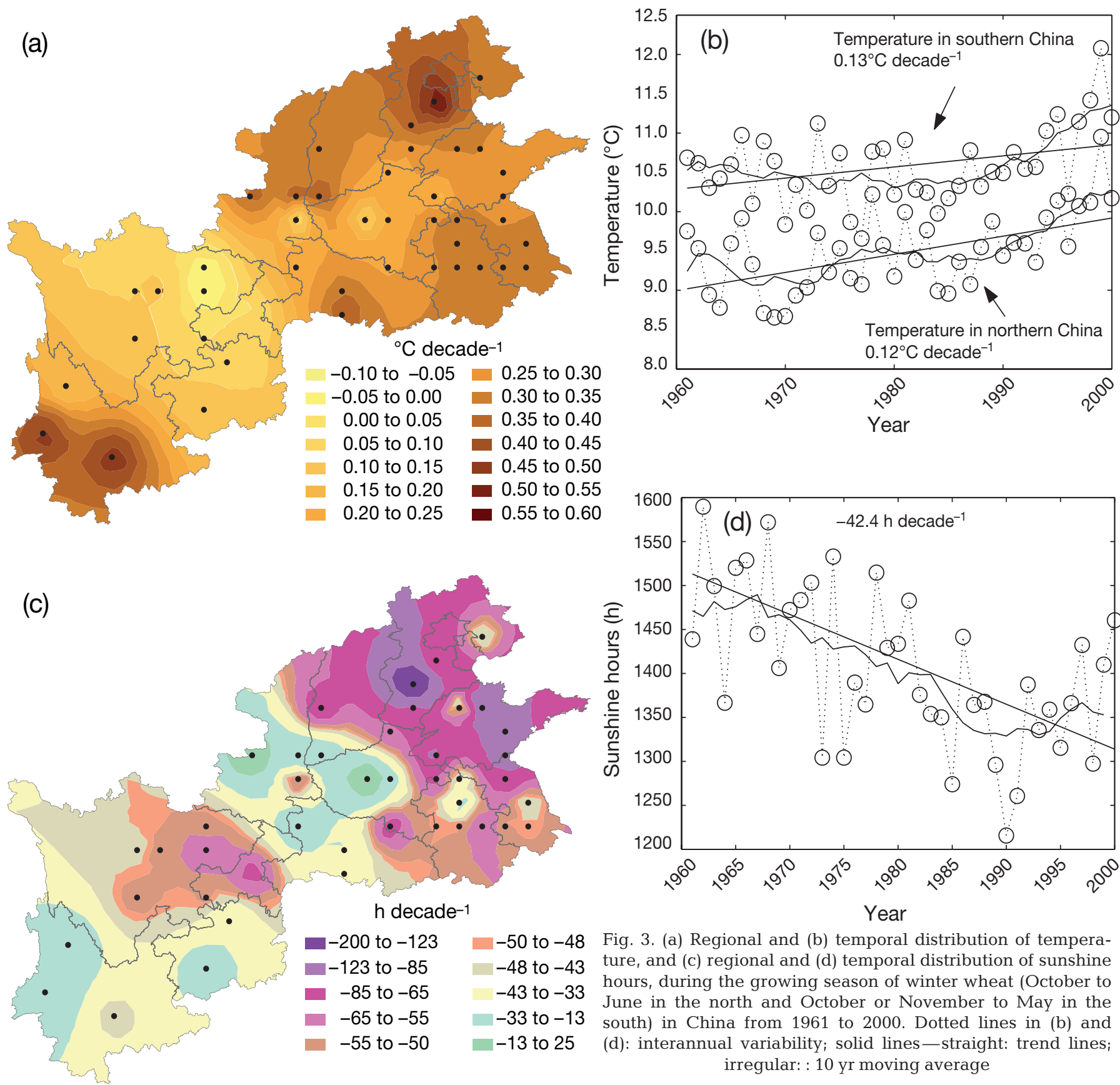

Fig. 3. (a) Regional and (b) temporal distribution of temperature, and (c) regional and (d) temporal distribution of sunshine hours, during the growing season of winter wheat (October to June in the north and October or November to May in the south) in China from 1961 to 2000. Dotted lines in (b) and (d): interannual variability; solid lines-straight: trend lines; irregular: : 10 yr moving average

\subsection{Simulated influence of climate change on potential yield}

Using the parameters determined by the tuning of the model and the observed long term weather data, simulations were made for all of the 50 stations in China from 1961-2000. It should be kept in mind that we assumed that there is no change in winter wheat variety and agricultural management. Doing so means that growth and yield can only be influenced by climate factors.
The simulated potential yields of winter wheat in northern and southern China as well as the trend of the potential yields in different regions, are given in Fig. 4. The potential yields increased in most parts of northern China (Hebei, Shandong, Shanxi and north of Henan), amounting to 55 to $322 \mathrm{~kg}$ decade $^{-1} \mathrm{ha}^{-1}$ in Hebei, north of Shandong and east of Shanxi. In addition, 19 of the 24 stations in northern China had positive trends, among which 8 stations show significant trends according to the Mann-Kendall test. However, the potential yield of winter wheat decreased in most 

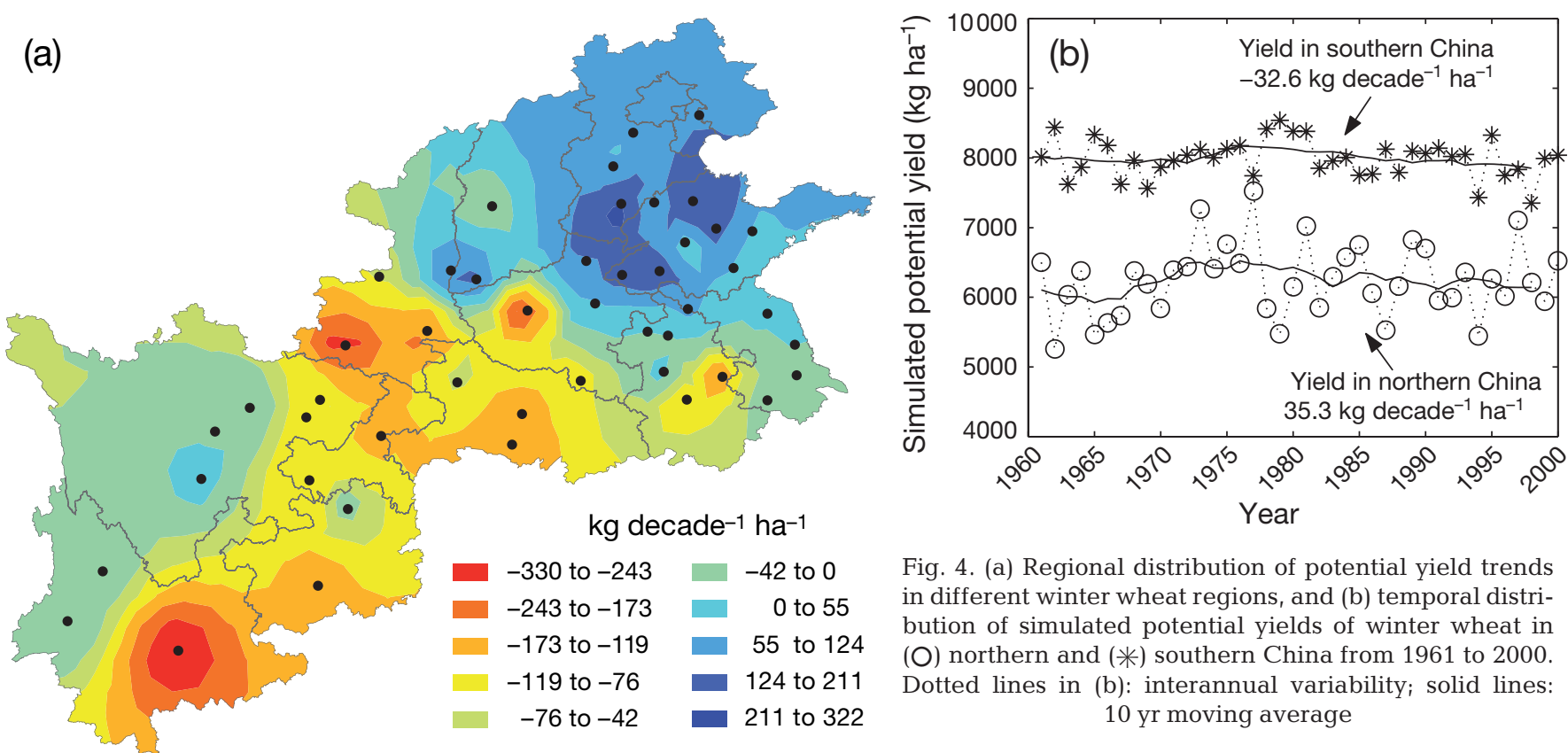

Fig. 4. (a) Regional distribution of potential yield trends in different winter wheat regions, and (b) temporal distribution of simulated potential yields of winter wheat in (O) northern and (*) southern China from 1961 to 2000 . Dotted lines in (b): interannual variability; solid lines: 10 yr moving average

parts of southern China. The reduction is more than $100 \mathrm{~kg} \mathrm{decade}^{-1} \mathrm{ha}^{-1}$ in parts of Anhui, Hubei, Sichuan, Chongqing, Guizhou and Yunnan. In southern China, the majority of the stations (21 of 26) had negative trends in potential yield, with 6 stations having significant negative trends. On average the potential yield in northern China increased by $35.3 \mathrm{~kg}$ decade $\mathrm{ha}^{-1}$, while yields decreased by $32.6 \mathrm{~kg}$ decade ${ }^{-1} \mathrm{ha}^{-1}$ in southern China. Thus, warming due to climate change predicts a positive effect on the potential yield for most parts of northern China and adverse effects for most parts of southern China. Furthermore, there is a greater interannual variability in northern than southern China. The potential yields of winter wheat are expected to be mainly influenced by temperature, since water supply is not limited in all regions. Thus, frequent low temperature in March and April in northern China may explain the relatively high variability.

In northern China, the winter wheat region encloses temperate, semi-humid and monsoon-controlled climatic zones, and the growth and yields of winter wheat are often affected by frost damage in winter (Jin 1996). Frost damage often happens in the northern China Plain and Huanghuai Plain due to cold air outbreaks from Mongolia. For example, frost damage was experienced over 5 winters from 1949 to 1953, with winter wheat yields decreasing by $30 \%$ in Beijing. In addition, about $30 \%$ of the winter wheat was destroyed by frost damage in Hebei in 1980. The damage to winter wheat caused by freezing depends on the formation of ice crystals within the tissue when the temperature is $<0^{\circ} \mathrm{C}$, although freezing-tolerant species can apparently withstand some ice formation. Membrane dam- age is a universal result of freezing damage, though it is still not certain whether it is the primary effect. As temperatures are $<0^{\circ} \mathrm{C}$, ice starts to form in the extracellular water (e.g. in the cell walls). Because ice has a lower vapor pressure (and chemical potential) than liquid water at the same temperature, extra-cellular freezing causes water to be removed from within the cells to the sites of extra-cellular freezing, which leads to rapid dehydration of the cell (Levitt 1980).

The damage to winter wheat induced by frost damage happens when the temperature is $<0^{\circ} \mathrm{C}$. There-

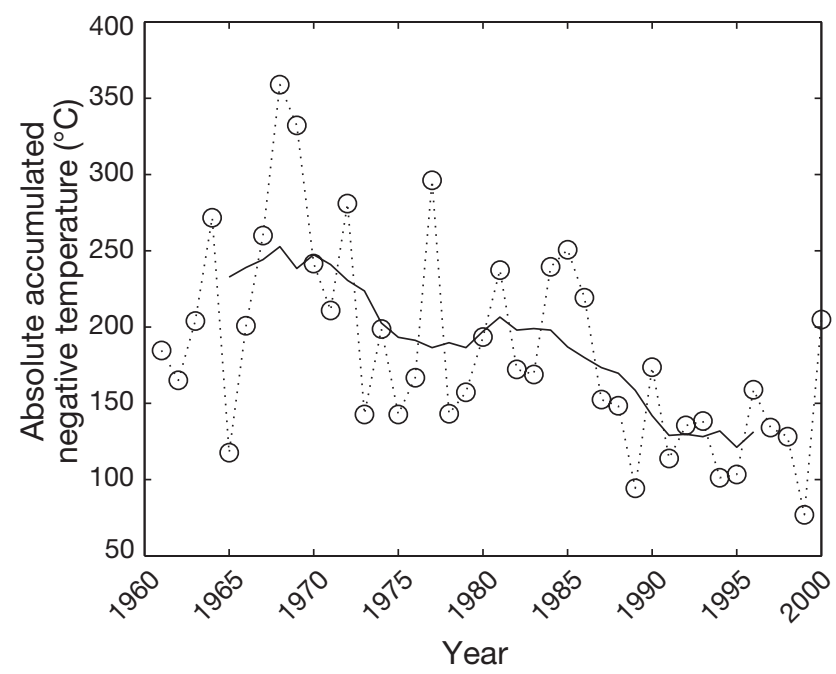

Fig. 5. Absolute value of accumulated negative temperature during winter (December to February in the following year) in Hebei, Shandong, east Shanxi and north Henan provinces from 1961 to 2000. Dotted line in (b): interannual variability; solid line: 10 yr moving average 
Table 2. Mean temperatures during growing season, and simulated growth and potential yields of winter wheat in southern China

\begin{tabular}{|lcccc|}
\hline & $1960 \mathrm{~s}$ & $1970 \mathrm{~s}$ & $1980 \mathrm{~s}$ & $1990 \mathrm{~s}$ \\
\hline $\begin{array}{l}\text { Mean temperature during } \\
\text { growing season }\left({ }^{\circ} \mathrm{C}\right)\end{array}$ & 10.2 & 10.2 & 10.3 & 11.3 \\
Simulated flowering period (d) & 104 & 104 & 105 & 98 \\
Simulated maturity period (d) & 133 & 133 & 133 & 128 \\
Simulated potential yield $\left(\mathrm{kg} \mathrm{hm}{ }^{-2}\right)$ & 7947.4 & 8150.8 & 7979.5 & 7893.1 \\
\hline
\end{tabular}

velopment rates are more rapid, resulting in a reduction of phenophase duration. Table 2 shows the growth dates and potential yield during 19612000 over southern China. The duration of the phenophases of flowering and maturity were clearly reduced in the $1990 \mathrm{~s}$ as compared to the $1960 \mathrm{~s}$ (a reduction of 6.0 and $4.8 \mathrm{~d}$ for flowering and maturity, respectively) due to the $1.1^{\circ} \mathrm{C}$ temperature increase

fore, accumulated negative temperatures during winter (December to February) can be calculated as an index of the degree of potential frost damage during winter. Fig. 5 shows the features of absolute value of the winter accumulated negative temperature in Hebei, Shandong, east of Shanxi and north of Henan. The absolute value of accumulated negative temperature decreased by $29.3^{\circ} \mathrm{C}$ decade $^{-1}$. Furthermore, it amounted to $129.5^{\circ} \mathrm{C}$ in the $1990 \mathrm{~s}$, which decreased $44.6 \%$ of that the amount experienced in the $1960 \mathrm{~s}$. To identify the role of accumulated negative temperatures on yield, the correlation coefficients between potential yields and absolute value of accumulated negative temperatures were calculated in Hebei, Shandong, east of Shanxi and north of Henan. All the stations show negative correlations, but only 8 stations have significant correlations. Thus, the accumulated negative temperatures clearly show an inverse relationship with potential yields. This indicates that the damage to winter wheat caused by frost damage had been lessened during 1961-2000 over most parts of northern China. This appears to be an important reason for the increased potential yield in northern China. The WOFOST model accounts for yield loss using a cold stress index which was modified and improved for this research based on the experiments of winter wheat in China (Jin 1996). For example, the death rate of winter wheat was $10 \%$ when temperature was $-12{ }^{\circ} \mathrm{C}$, while the death rate was $50 \%$ when temperature reached $-16.4^{\circ} \mathrm{C}$.

In southern China, most areas growing winter wheat are in warm and humid monsoon-controlled climatic zones where the temperatures in winter changed boy 0 to $5^{\circ} \mathrm{C}$. The growth of winter wheat is usually influenced by high temperature, floods and water damage. The possible reasons for the decreased simulated yield of winter wheat are shorter growing intervals brought about by the increased mean temperatures. Temperature influences plant growth and development through its effects on stomatal opening and rate of physiological processes. High temperatures can speed up the biochemical reactions and increase transpiration losses. Higher temperatures lead to an increased accumulation of degree-days, hence growth and de- between the 2 time periods. These results are in agreement with Sainia \& Nanda (1987) and Dhiman et al. (1985), who found that flowering and maturity dates were reduced by about $5 \mathrm{~d}$ and $4 \mathrm{~d}$ following a $1^{\circ} \mathrm{C}$ temperature increase in northwest India. As a result, a shorter growing period for winter wheat caused by increases in mean temperatures is inherently detrimental since there is less time for photosynthesis and accumulation of biomass and hence potential yield. This creates a potential problem for southern China which will get worse in the future due the ongoing warming trend.

To focus on the role played by temperature and climatic conditions other than precipitation, this study made the assumption that water is not limited. It should be kept in mind that this is a very big assumption and may not always be realistic in this part of the world. The conclusions drawn from the study are therefore not applicable for areas where irrigation is not possible.

Acknowledgements. This research is supported by grants from the Climate Change Special Fund of the China Meteorological Administration (CCSF2006-34), the Swedish Foundation for International Cooperation in Research and High Education, the Swedish Agency for International Development Cooperation and the Natural Science Foundation of China (40231006).

\section{LITERATURE CITED}

Alexandrov VA, Hoogenboom G (2000) The impact of climate variability and change on crop yield in Bulgaria. Agric For Meteorol 104:315-327

Bauer A, Fanning C, Enz JW, Eberlein CV (1984) Use of growing degree-days to determine spring wheat growth stages. ND State Univ Agric Extension Bull 37:11-16

Boogaard HL, van Diepen CA, Rötter RP (1998) WOFOST 7.1 User's guide for the WOFOST 7.1 crop growth simulation model and WOFOST Control Center 1.5, Technical Document 52. DLO Winand Staring Center, Wageningen

China Meteorological Administration (2000) Atlas of China, China Maps Publishing House, Beijing (in Chinese)

China Soil Survey Office (1995) Soil type record of China. China Agriculture Publishing House, Beijing (in Chinese)

CSY (2002) China statistical yearbook. National Bureau of Statistics of China, China Statistics Press, Beijing (in Chinese) 
CSY (2003) China statistical yearbook. National Bureau of Statistics of China, China Statistics Press, Beijing (in Chinese)

Dai XS (1997) Potential effects of climatic variation geographical distribution of wheat in China. J Appl Meteorol 8: 19-25 (in Chinese with English abstract)

Dhiman SD, Sarma HC, Singh DP (1985) Grain growth of wheat as influenced by time of sowing and nitrogen fertilization. Haryana Agric Univ J Res 15:158-163

Ding Y, Ren G, Shi G, Gong P and 10 others (2006) National assessment report of climate change. I: Climate change in China and its future trend. Adv Clim Change Res 2:3-8 (in Chinese with English abstract)

FAO (2002) The state of food and agriculture. Agriculture and global public goods ten years after the Earth Summit. Food and Agriculture Organization, Rome

Ge D, Jin Z, Shi C (2002) Gradual impact of climate change on rice production and adaptation strategies in southern China, Jiangsu. J Agr Sci 18:1-8 (in Chinese with English abstract)

Hamlyn G J (2000) Plants and microclimate (A quantitative approach to environmental plant physiology). Cambridge University Press, Cambridge

Hu Y, Ping L, Yang JG (2005) Applied meteorology. China Meteorological Press, Beijing

Hulme M, Barrow EM, Arnell NW, Harrisson PA, Johns TC, Downing TE (1999) Relative impacts of human-induced climate change and natural climate variability. Nature 397:688-691

IPCC (2001) Climate change: summary for policymakers and technical summary of the Working Group 1 Report. Cambridge University Press, Cambridge

Jin SB (1996) Winter wheat in China. China Agriculture Publishing House, Beijing, p 766-768 (in Chinese)

Lal M, Singh KK, Srinivasan G, Rathore LS, Naidu D, Tripathi CN (1999) Growth and yield responses of soybean in Madhya Pradesh, India to climate variability and change. Agric For Meteorol 93:53-70

Lanen, HAJ, van Diepen CA, Reinds GJ, de Kening GHJ, Bulens JD, Bregt AK (1992) Physical land evaluation methods and GIS to explore the crop growth potential and its effects within the European Communities. Agr Syst 39: $307-328$

Levitt J (1980) Responses of plants to environmental stresses, 2nd edn, I \& II. Academic Press, New York

Lin E, Wang H, Wang J (1997) Modeling the impacts of global climate change on Chinese agriculture. Agriculture Technology Publishing House, Beijing (in Chinese)

Mavromatis T, Jones PD (1999) Evaluation of HADCM2 and direct use of daily GCM data in impact assessment studies. Clim Change 41:583-614

Morison JIL, Gifford RM (1984) Plant growth and water use with limited water supply in high $\mathrm{CO}_{2}$ concentration. I. Leaf area, water use and transpiration. Aust J Plant Physiol 11:361-374

NCC (National Climate Center) (2000) China climate impact assessment. Meteorological Publishing House, Beijing (in Chinese)

Penman HL (1948) Natural evaporation from open water, bare soil and grass. Proc R Soc Ser A 193:120-146

Qian WH, Chen D, Lin Q, Qin WM (2004) Regional temperature and precipitation trend under global change. Newsletter Clim Change 3:8-9 (in Chinese)

Qian Y, Kaiser DP, Leung LR, Xu M (2006) More frequent cloud-free sky and less surface solar radiation in China from 1955 to 2000. Geophys Res Lett 33:1-4, L01812, doi: 10.1029/2005GL024586

Editorial responsibility: Gregory Jones, Ashland, Oregon, USA
Riha SJ, Wilks DS, Simoens P (1996) Impact of temperature and precipitation variability on crop model predictions. Clim Change 32:293-311

Rötter R (1993) Simulation of the biophysical limitations to maize production under rainfed conditions in Kenya. Evaluation and application of the model WOFOST. Materialien zur Ostafrika-Forschung, Heft 12. Geographischen Gesellschaft, Trier

Sainia AD, Nanda R (1987) Analysis of temperature and photoperiod response to flowering in wheat. Indian J Agr Sci 57:351-359

Savin I, Stolbovoy V, van Diepen CA (2001) Crop growth simulation model WOFOST and its application for land productivity analysis in Russia. Russian Academy of Agricultural Science, VV Dokuchaev Soil Science Institute and Alterra Winand Staring Center for Integrated Land, Soil and Water Research, Wageningen

Supit I, Hooijer AA, van Diepen CA (1994) System description of the WOFOST 6.0 crop growth simulation model. Joint Research Center, Commission of the European Communities, Brussels

Tang HY, Zhai PM, Wang ZY (2005) Change in mean maximum temperature, minimum temperature and diurnal rang in China during 1951-2002. Clim Env Res 10: 728-735 (in Chinese with English abstract)

Tao F, Yokozawa M, Zhang Z, Hayashi Y, Grassl H, Fu C (2004) Variability in climatology and agricultural production in China in association with the East Asian summer monsoon and El Niño Southern Oscillation. Clim Res 28:23-30

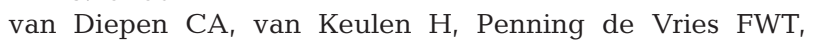
Noy IGAM, Goudriaan J (1987) Simulated variability of wheat and rice yields in current weather conditions and in future weather when ambient $\mathrm{CO}_{2}$ had doubled. Simulation reports CABO-TT 14 . University of Wageningen

Wang ZY, Ding YH, He JH, Yu J (2004) An updating analysis of the climate change in China in recent 50 years. Acta Meteorol Sin 62:228-236

Wolf J (1993) Effects of climate change on wheat and maize production potential in the EC. In: Kenny GJ, Harrison PA, Parry ML (eds) The effect of climate change on agricultural and horticultural potential in Europe. Research report 2. Environmental change unit, University of Oxford, Oxford, p 93-119

Wolf J, van Diepen CA (1991) Effects of climate change on crop production in the Rhine basin. Report 52. The Winand Staring Center for Integrated Land, Soil and Water Research, Wageningen

Wolf J, Berkhout JAA, van Diepen CA, van Immerzeel $\mathrm{CH}$ (1989) A study on the limitations to maize production in Zambia using simulation models and geographic information system. In: Bouma J, Brecht AK (eds) Land qualities in space and time, Proc Symp Org Int Soc Soil Sci, Wageningen, p 22-26

Wu DR (2003) The applicability research of WOFOST model in North China Plain. Acta Phytoecol Sin 27:594-602 (in Chinese with English abstract)

Xiong W, Tao FL, Xu YL (2001) Simulation of rice yield under climate changes in future in China. Chin J Agrometeorol 22:1-5 (in Chinese with English abstract)

Zhai PM, Ren FM, Zhang Q (1999) Detection of trends in China's precipitation extremes. Acta Meteorol Sin 57: 208-216 (in Chinese with English abstract)

Zhang Y, Wang F (1998) The possible impacts of climate warming on rice production in China. Acta Meteorol Sin 56:369-376 (in Chinese with English abstract)

Submitted: December 10, 2005; Accepted: July 27, 2006

Proofs received from author(s): September 27, 2006 